\title{
Contributions of Chinese-style cooking and incense burning to personal exposure and residential PM concentrations in Taiwan region
}

\author{
Chung-Min Liao*, Szu-Chieh Chen, Jein-Wei Chen, Huang-Min Liang \\ Ecotoxicological Modeling Center, Department of Bioenvironmental Systems Engineering, National Taiwan University, \\ Taipei 10617, Taiwan, Republic of China
}

Received 8 October 2004; accepted 22 March 2005

Available online 31 May 2005

\begin{abstract}
We investigated the effect of indoor sources including Chinese-style cooking, incense burning, cleaning, and people's moving on indoor particle size distributions and concentrations and calculated the personal exposure dose rates in the human respiratory tract (HRT) using time-activity and indoor and outdoor particle size distribution data collected from a traditional Taiwanese residence in central Taiwan region. We applied a simple size-dependent indoor air quality model associated with a compartmental lung model to determine the source emission rates and exposure dose. Cooking and incense burning had sizeintegrated source emission rates of $0.042 \pm 0.024$ (mean \pm S.D.) and $0.038 \pm 0.026$ particles s $^{-1}$, respectively. Cooking and incense burning were significant contributors to indoor particle levels for particle sizes from 0.5 to $5 \mu \mathrm{m}$ in that the percent contributions to indoor concentrations were $0.334 \pm 0.02$ and $0.267 \pm 0.035$, respectively. Our results demonstrated that extrathoracic (ET) region had higher average PM mass lung/indoor ratio (0.77) than that of bronchial (BB) (0.52), bronchiolar (bb) (0.27) and alveolar-interstitial (AI) (0.14) regions from both cooking and incense burning events. The average integrated deposition dose rates (particles $\mathrm{cm}^{-2} \mathrm{~h}^{-1}$ ) of $24.11 \mathrm{in} \mathrm{ET,} 4.68 \mathrm{in} \mathrm{BB}$, and $7.89 \mathrm{in}$ bb were higher than that of 0.011 in AI for both cooking and incense burning events. This research illustrates that exposure assessment based on time-activity and real-time behavior of particle data can provide valuable information on the fate of indoor particles and hazard to human health. (C) 2005 Elsevier B.V. All rights reserved.
\end{abstract}

\footnotetext{
* Corresponding author. Tel.: +886 2 23634512; fax: +886 2 23626433 .

E-mail address: cmliao@ntu.edu.tw (C.-M. Liao).
}

\section{Introduction}

High associations between exposure to indoor air pollution from Chinese-style cooking and risk of lung cancer among Chinese females have recently been found in residential settings (Zhong et al., 1999). 
The generation rates and emission factors of particulate matter (PM) from incense burning and personal exposure were also assessed in both the laboratory and residential settings (Lung and $\mathrm{Hu}, 2003$; Lung et al., 2003). Epidemiological studies have shown that the potentially adverse health effects of incense burning include increase of risk of leukemia for children whose parents burned incense (Lowengart et al., 1987) and childhood brain tumors associated with maternal contact with incense burning (Preston-Martin et al., 1982). Estimation of parameters affecting indoor exposures including source emission rates, deposition rates, and air exchange rates is very difficult because of the numerous factors influencing these parameters, such as wind speed, wind direction, indoor and outdoor temperatures, and housing structure (Liao et al., 2003).

Several studies have estimated deposition rates indoors, although there is considerable variability in the methods used and types of particle examined (Crump and Seinfeld, 1981; Lai and Nazaroff, 2000). Depending on the flow regime, different models have been proposed for particle deposition in a ventilated airspace. In a ventilated airspace, Brownian and turbulent diffusion, sedimentation, and laminar as well as convective flow exist to varying degrees and lead to particle deposition onto walls and other surfaces. Apart from deposition, independently measuring the penetration efficiencies of particles is very difficult. In our present study, we assumed that the penetration of particles is totally induced by wind- induced natural ventilation. Natural ventilation is widely used in Taiwanese residences with the advantages of saving energy, expense, and installation time in that houses are controlled by natural convection to remove excessive heat and moisture. The mechanism of natural ventilation depends on wind effects, thermal buoyancy, and the combination of both wind and buoyancy forces. Wind speed and wind direction are the dominant factors for wind-induced effects (Liao et al., 2004).

A complete particle exposure model for human respiratory tract (HRT) includes airflow dynamic, physiological, lung morphological, and dose cumulated submodels. Numerous mathematical models for predicting PM deposition in the HRT have been developed over the years (ICRP, 1994). In this present study, we employed an approach based on the concept of applying compartmental modeling to the human lung anatomy incorporated with the ICRP66 recommended model (ICRP, 1994).

The purposes of this study are twofold: (1) to determine the source emission rates from Chinesestyle cooking and incense burning and (2) to calculate PM doses and lung/indoor PM ratios from above sources in a traditional Taiwanese residence. We focused on characterizing the indoor/outdoor/personal exposure relationships of PM in a single house incorporated with detailed measurements of PM characteristics from major activities indoors including cooking, cleaning, incense burning, and people's moving and the house environment under realistic conditions.

\section{Materials and methods}

\subsection{Data collection}

An experiment was carried out to characterize the PM size distribution and PM levels for the existing ambient PM in a nonsmoking household situated in Changhwa in the central Taiwan region for a 10-day sampling period during January $18-27,2003$. The house is $6.0 \times 6.0 \times 3.0 \mathrm{~m}^{3}$. The main space is occupied by the living room, altar and kitchen. Indoor air temperature and relative humidity were measured to be $24 \pm 1.5{ }^{\circ} \mathrm{C}$ and $70 \pm 4 \%$, respectively.

Most measurements were in the wind-induced natural ventilation conditions. The natural ventilation rate depends on the effect of wind moving through openings (Liao et al., 2004). The air exchange rate can be expressed as $\lambda_{\mathrm{n}}=Q_{\mathrm{n}} / V$ where $\lambda_{\mathrm{n}}$ is the air change rate $\left(\mathrm{h}^{-1}\right), Q_{\mathrm{n}}$ is the natural ventilation rate $\left(\mathrm{m}^{3} \mathrm{~h}^{-1}\right)$, and $V$ is the volume of the airspace $\left(\mathrm{m}^{3}\right)$. The detailed algorithm for determining the values of air exchange rate can be found in Liao et al. (2004). We used data logger to collect and to record the velocity and temperature. The measured air exchange rates were ranged from a minimum of $0.07 \mathrm{~h}^{-1}$ to a maximum of $3 \mathrm{~h}^{-1}$ with an overall arithmetic mean 
of $0.7 \mathrm{~h}^{-1}$ and a lognormal distribution with geometric mean $0.52 \mathrm{~h}^{-1}$ and a geometric standard deviation 1.82 (i.e., $\left.\mathrm{LN}\left(0.52 \mathrm{~h}^{-1}, 1.82\right)\right)$.

Sampling interval was divided into several certain periods on a daily basis: 11:00-12:00 and 17:00-18:00 for cooking (stir-frying, decocting, deep-frying); 6:00-8:00 and 22:00-24:00 for incense (Taiwan yellow joss stick) burning; 10:00-11:00 for people's moving (walking around, children playing); 14:00-15:00 for cleaning (sweeping, vacuuming); and the ventilation-induced outdoor PM characteristics were also measured. The monitoring equipment was placed in a single indoor location (1.5 $\mathrm{m}$ above the floor), adjacent to areas of the kitchen, altar, and living room where the housing activities occurred.

A portable laser dust monitor (Series 1100, Grimm Labortechnik GmbH and Co. KG, Ainring, Germany; referred to as DM1100) was used to analyze the indoor and outdoor PM characteristics. The DM1100 combines the principles of aerodynamic particle size separation and light scattering particle detection. The outputs from DM1100 can be expressed both as $\mu \mathrm{g} \mathrm{m}^{-3}$ and as particles $\mathrm{L}^{-1}$ per 5 seconds. The AED of the particles can range from 0.5 to $10 \mu \mathrm{m}$. The DM1100 measured dust mass concentration in the range of 1.0 to $50,000 \mu \mathrm{g} \mathrm{m}{ }^{-3}$. Measured channels are in the ranges of $0.5-1,1-2,2-5$, and 5-10 aerodynamic diameter. Before the measurements, the DM1100 was calibrated with known particles of Uniform Latex Microspheres Polystyrene $(0.5 \mu \mathrm{m})$ and Polymer Microspheres Styrene Binyltoluene (3 $\mu \mathrm{m})$ (Duke Scientific, Palo Aoto, CA).

\subsection{Indoor source contribution estimations}

We modified a well-developed indoor/outdoor (I/O) ratio model that based on the assumption of well-mixed conditions (Abt et al., 2000; Liao et al., 2003) to calculate the indoor source-dependent, size-specific, and timeaveraged PM mass I/O ratio,

$$
\frac{C_{\mathrm{I}}(k, t)}{C_{\mathrm{o}}(k, t)}=\frac{\lambda_{\mathrm{n}}(t)}{\lambda_{\mathrm{n}}(t)+\lambda_{\mathrm{d}}(k, t)}\left[1+\frac{G_{i s}(k)}{Q_{\mathrm{n}}(t) C_{\mathrm{o}}(k, t)}\right], k=1,2, \cdots, N,
$$

where $C_{\mathrm{I}}(k, t)$ is the time-dependent indoor PM concentration in the $k$ th size range $\left(\mu \mathrm{g} \mathrm{m}^{-3}\right) ; C_{\mathrm{o}}(k, t)$ is the timedependent outdoor PM concentration in the $k$ th size range $\left(\mu \mathrm{g} \mathrm{m}^{-3}\right) ; \lambda_{\mathrm{n}}(t)$ is the air exchange rate of natural ventilation through open windows and doors $\left(\mathrm{h}^{-1}\right)$ in which $\lambda_{\mathrm{n}}(t)=Q_{\mathrm{n}}(t) / V, Q_{\mathrm{n}}(t)$ is the natural ventilation rate $\left(\mathrm{m}^{3}\right.$ $\left.\mathrm{h}^{-1}\right) ; V$ is the air volume $\left(\mathrm{m}^{3}\right) ; \lambda_{\mathrm{d}}(k, t)$ is the deposition rate of indoor PM due to Brownian and turbulent diffusive deposition and gravitational sedimentation in the $k$ th size range $\left(\mathrm{h}^{-1}\right) ; k$ is the size range number; $G_{\text {is }}(k)$ is the mass flux generated by indoor source $i$ in the $k$ th size range $\left(\mu \mathrm{g} \mathrm{h}^{-1}\right)$, and $N$ is assigned to be the end point number for a $k$ th size range, $d_{k}$ and $d_{k+1}$. The particles are divided into geometrically equal sized bins in the size range of interest. The PM concentration is assumed to be a constant AED within each bin size. The end points, $d_{k}$ and $d_{k+1}$, of the $k$ th bin size are considered to be equal to the geometric mean of the end points of the bin size as, $d_{k}=d_{\min }+\left[\left(d_{\max }-d_{\min }\right)(k-1)\right] /(N-1)$, where particles smaller than $d_{\min }$ (the minimum diameter) are considered to be the finest, and $d_{\max }$ is the largest particle size of interest.

The mass flux generated from indoor sources attributed to four major indoor activities of cooking, cleaning, incense burning, and people moving may be expressed as (Abt et al., 2000; Chang et al., 2003),

$$
G_{i s}(k, t)=\sum_{i=1}^{4} \frac{T_{i} S_{i}(k, t)}{t_{i}},
$$

where $T_{i}$ is the time spent for specific indoor activity $i(\mathrm{~h}), S_{i}(k, t)$ is the emission rate or PM mass generated per hour of specific activity $i$ in the $k$ th size range $\left(\mu \mathrm{g} \mathrm{h}^{-1}\right)$, and $t_{i}$ is the duration of the sampling period for specific indoor activity $i$ (h). Substituting Eq. (2) into Eq. (1), we obtain

$$
C_{\mathrm{I}}(k, t)=\beta_{\mathrm{o}}(k, t) C_{\mathrm{o}}(k, t)+\sum_{i=1}^{4} \beta_{i}(k, t) T_{i},
$$


where $\beta_{\mathrm{o}}(k, t)=\lambda_{\mathrm{n}} /\left(\lambda_{\mathrm{n}}+\lambda_{\mathrm{d}}(k, t)\right)$ is equivalent to the PM I/O ratio when no PM generated from indoor sources (dimensionless); and $\beta_{i}(k, t)=S_{i}(k, t) /\left(\lambda_{\mathrm{n}}+\lambda_{\mathrm{d}}(k, t) V t_{i}\right)$ is the size-dependent effective emission rate from indoor source $i\left(\mu \mathrm{g} \mathrm{m}^{-3} \mathrm{~h}^{-1}\right)$ in a sampling period $t_{i}$, accounting for PM losses from air exchange and deposition.

We used a multiple linear regression technique to estimate the contribution of indoor sources and outdoor concentrations to indoor concentrations and activity-based source emission rates for each size bin. Based on Eq. (3) and incorporation of other unrecorded indoor sources, we can estimate slopes and intercepts using standard regression methods to obtain the effective emission rates for the four major indoor activities following a linear model as,

$$
C_{\mathrm{m}}(k, t)=\beta_{\mathrm{int}}+\sum_{i=1}^{4} \beta_{i}(k, t) T_{i}+\beta_{\mathrm{o}}(k, t) C_{\mathrm{o}}(k, t)+\varepsilon,
$$

where $C_{\mathrm{m}}(k, t)$ is the measured size-dependent indoor PM concentrations, $\beta_{\text {int }}$ is the intercept that represents the contribution of indoor sources not accounted for by the recorded activities or outdoor concentrations, and $\varepsilon$ denotes the residual representing the error in the point prediction of $C_{\mathrm{m}}(k, t)$. The methods of statistical analysis employed by Abt et al. (2000) for parameter estimates were also applied to our work. We used generalized estimating equations to estimate source emission rates in 20-min intervals for each size bin in that a nonparametric method allows correlated measurements over time to be modeled. A time-series autoregressive error structure was used for this model to allow the model to account for correlations between 20-min periods within a sampling day. All statistical analyses were conducted using the Statistica ${ }^{\circledR}$ software (StatSoft, Tulsa, OK, USA). All concentrations are expressed as number concentrations $\left(\mathrm{cm}^{-3}\right)$ in place of $\mu \mathrm{g} \mathrm{m}^{-3}$ in Eq. (1).

\subsection{PM lung/indoor relationships}

We divided HRT into five major compartments from the suggestion of ICRP66 (ICRP, 1994): (i) the nasal passage $\left(\mathrm{ET}_{1}\right)$, (ii) pharynx $\left(\mathrm{ET}_{2}\right)$, (iii) the bronchial region (BB), (iv) the bronchiolar region (bb), and (v) alveolarinterstitial region (AI). We employed a lung/indoor (L/I) ratio model (Liao et al., 2003) to calculate the PM L/I ratio,

$$
\begin{aligned}
& \frac{C_{1}(k, t)}{C_{\mathrm{I}}(k, t)}=\frac{-\frac{Q}{V_{1}}\left(L_{33} L_{44} L_{55}-L_{33} \beta_{45} \frac{Q}{V_{4}} \beta_{54} \frac{Q}{V_{5}}-L_{55} \beta_{34} \frac{Q}{V_{3}} \beta_{43} \frac{Q}{V_{4}}\right)}{\|L(k)\|}, \\
& \frac{C_{3}(k, t)}{C_{\mathrm{I}}(k, t)}=\frac{\frac{Q}{V_{1}} \beta_{31} \frac{Q}{V_{3}}\left(L_{44} L_{55}-\beta_{45} \frac{Q}{V_{4}} \beta_{54} \frac{Q}{V_{5}}\right)}{\|L(k)\|}, \\
& \frac{C_{4}(k, t)}{C_{\mathrm{I}}(k, t)}=\frac{-\frac{Q}{V_{1}} \beta_{31} \frac{Q}{V_{3}} \beta_{43} \frac{Q}{V_{4}} L_{55}}{\|L(k)\|}, \\
& \frac{C_{5}(k, t)}{C_{\mathrm{I}}(k, t)}=\frac{\frac{Q}{V_{1}} \beta_{31} \frac{Q}{V_{3}} \beta_{43} \frac{Q}{V_{4}} \beta_{54} \frac{Q}{V_{5}}}{\|L(k)\|},
\end{aligned}
$$

where $C_{i}(k, t) / C_{\mathrm{I}}(k, t), i=1,2,3,4,5$ represents the PM L/I ratios for compartments $\mathrm{ET}_{1}, \mathrm{ET}_{2}$, BB, bb, and AI, respectively, $Q$ is the breathing rate $\left(\mathrm{cm}^{3} \mathrm{~h}^{-1}\right) ; V_{i}$ is the volume of compartment $i\left(\mathrm{~cm}^{-3}\right) ; \beta_{m n}$ is the transition 
coefficient from compartments $n$ to $m$; the constant input matrix $[B]=\operatorname{diag}\left[Q / V_{1}, 0,0,0\right]$, and $\|L(k)\|$ is a determinant of $[L(k)]$ and has the form as

$$
\left[\begin{array}{llll}
-\lambda_{\mathrm{d}_{1}}(k)-\lambda_{\mathrm{s}_{1}}(k)-\lambda_{i m_{1}}(k) & \beta_{13} \frac{Q}{V_{1}} & 0 & 0 \\
-\varepsilon_{1}(k) \frac{Q}{V_{1}}-\beta_{31} \frac{Q}{V_{1}}-\frac{Q}{V_{1}} & -\lambda_{\mathrm{d}_{3}}(k)-\lambda_{\mathrm{s}_{3}}(k)-\lambda_{i m_{3}}(k) & Q & 0 \\
\beta_{31} \frac{Q}{V_{3}} & -\varepsilon_{3}(k) \frac{Q}{V_{3}}-\beta_{43} \frac{Q}{V_{3}}-\beta_{13} \frac{Q}{V_{3}} & \beta_{34} \frac{Q}{V_{3}} & -\lambda_{\mathrm{d}_{4}}(k)-\lambda_{\mathrm{s}_{4}}(k)-\lambda_{i m_{4}}(k) \\
0 & \beta_{43} \frac{Q}{V_{4}} & -\varepsilon_{4}(k) \frac{Q}{V_{4}}-\beta_{54} \frac{Q}{V_{4}}-\beta_{34} \frac{Q}{V_{4}} & \beta_{45} \frac{Q}{V_{4}} \\
0 & 0 & \beta_{54} \frac{Q}{V_{5}} & -\lambda_{\mathrm{d}_{5}}(k)-\lambda_{\mathrm{s}_{5}}(k)-\lambda_{i m_{5}}(k) \\
0 & & -\varepsilon_{5}(k) \frac{Q}{V_{5}}-\beta_{45} \frac{Q}{V_{5}}-C_{\mathrm{L}}(t)
\end{array}\right],
$$

in that $\lambda_{\mathrm{d}_{i}}(k), \lambda_{\mathrm{s}_{i}}(k)$, and $\lambda_{\mathrm{im}_{i}}(k)$ represent turbulent diffusive deposition rate, gravitational settling rate, and inertial impaction rate, respectively, in the $k$ th size range in the compartment $i\left(\mathrm{~s}^{-1}\right) ; \varepsilon_{i}(k)$ is the interception deposition efficiency in the $k$ th size range in the compartment $i ; C_{\mathrm{L}}(t)$ is the time-dependent PM clearance rate in the compartment $\mathrm{AI}\left(\mathrm{s}^{-1}\right)$, and $L_{i i}=L_{i i}(k)$ is the diagonal element of $[L(k)]$.

\subsection{PM deposition estimations}

The deposition model used to describe indoor PM deposit in a naturally ventilated airspace is derived from Crump and Seinfeld (1981) and is referred to as the C-S model. The turbulent flow paradigm appears to be best

Table 1

Rate equations of PM deposition for naturally ventilated airspace and for human respiratory tract (see Table 2 for description of symbols)

Naturally ventilated airspace

$\lambda_{\mathrm{d}}(k)=\frac{1}{d_{k+1}-d_{k}} \int_{d_{k}}^{d_{k+1}} \lambda_{\mathrm{d}}\left(d_{\mathrm{p}}\right) d\left(d_{\mathrm{p}}\right)$

where $\lambda_{\mathrm{d}}\left(d_{\mathrm{p}}\right)=\frac{1}{l w h}\left\{(2 w h+2 h l)\left(\left(\sin \frac{\pi}{n}\right)\left(k_{\mathrm{e}} D\left(d_{\mathrm{p}}\right)^{n-1}\right)^{1 / n}\right)+w l v_{\mathrm{s}}\left(d_{\mathrm{p}}\right)\right\} \operatorname{coth}\left(\frac{\pi v_{\mathrm{s}}\left(d_{\mathrm{p}}\right)}{2\left(n \sin \frac{\pi}{n}\right)\left(k_{\mathrm{c}} D\left(d_{\mathrm{p}}\right)^{n-1}\right)^{1 / n}}\right)$

$D\left(d_{\mathrm{p}}\right)=\frac{k_{\mathrm{B}} T C_{\text {slip }}}{3 \pi \eta_{a} d_{p}}$

$v_{\mathrm{s}}\left(d_{\mathrm{p}}\right)=\frac{\rho_{\mathrm{p}} g d_{\mathrm{p}}^{2}}{18 \eta_{\mathrm{a}}} C_{\text {slip }}\left(1-\frac{\rho_{\mathrm{a}}}{\rho_{\mathrm{p}}}\right)$

Slip correlation factor: $C_{\text {slip }}=\left(1+\frac{\lambda}{d_{\mathrm{p}}}\left(2.541+0.8 \exp \left(-0.55 \frac{d_{\mathrm{p}}}{\lambda}\right)\right)\right)$

Human respiratory tract ${ }^{\mathrm{c}}$

$\lambda_{d_{i}}\left(d_{\mathrm{p}}\right)=\frac{8}{D_{i}} \sin \frac{\pi}{n}\left(k_{\mathrm{e}} D\left(d_{\mathrm{p}}\right)^{n-1}\right)^{1 / n}$

$\lambda_{s_{i}}\left(d_{\mathrm{p}}\right)=\frac{4 v_{\mathrm{s}}\left(d_{p}\right)}{D_{i}} \operatorname{coth}\left(\frac{\pi v_{\mathrm{s}}\left(d_{\mathrm{p}}\right)}{2\left(n \sin \frac{\pi}{n}\right)\left(k_{\mathrm{e}} D\left(d_{\mathrm{p}}\right)^{n-1}\right)^{1 / n}}\right)$

$\lambda_{i m_{i}}\left(d_{\mathrm{p}}\right)=\frac{\rho_{\mathrm{p}} d_{\mathrm{p}}^{2} C_{s l i p} g}{9 \eta_{\mathrm{a}} D_{i}}=S t k \frac{g}{U_{i}}$, where Stk=Stokes number

$\varepsilon_{i}\left(d_{\mathrm{p}}\right)=\frac{(1-\alpha) \frac{n_{i}}{\sum^{n_{i}}} \frac{d_{\mathrm{p}}}{D_{i}}}{K u\left(1+\frac{d_{p}}{D_{i}}\right)}$

Kawabara number: $K u=-\frac{\ln \alpha}{2}-\frac{3}{4}+\alpha-\frac{\alpha^{2}}{4}$

\footnotetext{
${ }^{\text {a }}$ Derived from Crump and Seinfeld (1981).

b Adopted from Hinds (1999).

c The integrated formula for the $k$ th bin is the same as Eq. (T-1).
} 
applicable to the building scenario where ventilation (natural or forced) is the primary source of turbulent. The $\mathrm{C}-\mathrm{S}$ model is a well-established general model for the rate of aerosol deposition due to turbulent diffusion, Brownian diffusion, and gravitational sedimentation in a turbulently mixed arbitrary shape of airspace. The main features of the PM deposition model in the ventilated airspace and in the human respiratory tract are listed in Table 1 . Table 2 gives the input values of lung physiological information and deposition rate parameters used in the model calculations for naturally ventilated airspace and lung regions.

We also employed a time-dependent model to estimate PM size-dependent deposition rate from our data collections to make a comparison between theoretical (i.e., C-S model) and empirical determined values. Estimates obtained from collected data during periods where emissions from a dominant indoor source were followed by a nonsource period with relatively constant air exchange rates. An exponential equation can be used to describe the deposition of indoor PM in the conditions of air exchange rates and outdoor concentrations are constant during the decay period and that indoor concentrations are well-mixed (Abt et al., 2000; Howard-Reed et al., 2003),

$$
C_{(t)}(k)=e^{-\left(\lambda_{\mathrm{n}}+\lambda_{\mathrm{d}, \mathrm{m}}(k)\right) t} C_{(t-1)}(k),
$$

where $C_{(t)}(k)$ and $C_{(t-1)}(k)$ are the size-dependent indoor concentrations at times $t$ and $t-1$, respectively $(\mu \mathrm{g}$ $\left.\mathrm{m}^{-3}\right) ; \lambda_{\mathrm{n}}+\lambda_{\mathrm{d}, \mathrm{m}}(k)$ may be referred to as the overall system decay rate $\left(\mathrm{h}^{-1}\right)$; and $\lambda_{\mathrm{d}, \mathrm{m}}(k)$ is the size-dependent PM

Table 2

A summary of input parameters appearing in model implementation

\begin{tabular}{|c|c|c|}
\hline Parameter & Description & Representation Values \\
\hline \multicolumn{3}{|c|}{ Lung physiological parameters ${ }^{\mathrm{a}}$} \\
\hline$Q_{\mathrm{f}}$ & Breathing frequency & \\
\hline $\mathrm{ET}_{1}$ & & 15 breaths $\min ^{-1}$ \\
\hline $\mathrm{ET}_{2}$ & & 20 breaths $\min ^{-1}$ \\
\hline$V_{t}$ & Tidal volume & \\
\hline $\mathrm{ET}_{1}$ & & $1.33 \mathrm{~L}$ \\
\hline $\mathrm{ET}_{2}$ & & $3 \mathrm{~L}$ \\
\hline$D_{i}$ & Diameter of airways for breath & \\
\hline$D_{1(\mathrm{ET} 1)}$ & & $0.5 \mathrm{~cm}$ \\
\hline$D_{1(\mathrm{ET} 2)}$ & & $1.8 \mathrm{~cm}$ \\
\hline$D_{2}, D_{3}, D_{4}, D_{5}$ & & $2.3,1.2,0.1,0.05 \mathrm{~cm}$ \\
\hline$V_{i}$ & Volume of compartments in lung & \\
\hline$V_{1(\mathrm{ET} 1)}$ & & $5.8 \mathrm{~cm}^{3}$ \\
\hline$V_{1(\mathrm{ET} 2)}$ & & $21.3 \mathrm{~cm}^{3}$ \\
\hline$V_{2}, V_{3}, V_{4}, V_{5}$ & & $82.1,94.6,510.2,1580.4 \mathrm{~cm}^{3}$ \\
\hline$n_{1}, n_{2}, n_{3}, n_{4}, n_{5}$ & Number of airways & $1,1,1,6.5 \times 10^{4}, 4.5 \times 10^{7}$ \\
\hline$C_{\mathrm{L}}$ & Clearance rate by phagocyte & $8.3 \times 10^{-3} \mathrm{~h}^{-1}$ \\
\hline$\beta_{i j}$ & Transfer coefficient between compartments $i$ and $j$ & $0.9-1.1$ \\
\hline \multicolumn{3}{|c|}{ Deposition rate parameters } \\
\hline$n$ & Exponent constant & $2^{\mathrm{b}}$ \\
\hline$k_{\mathrm{e}}$ & Turbulent intensity parameter & $0.1 \mathrm{~s}^{-1 \mathrm{~b}}$ \\
\hline$k_{\mathrm{B}}$ & Boltzmann's constant & $1.38 \times 10^{-16}$ dyn $\mathrm{cm}^{\circ} \mathrm{C}^{-1 \mathrm{c}}$ \\
\hline$T$ & Ambient temperature & $29{ }^{\circ} \mathrm{C}$ \\
\hline$\eta_{\mathrm{a}}$ & Dynamic viscosity of air & $1.85 \times 10^{-4} \mathrm{~g} \mathrm{~cm}^{-1} \mathrm{~s}^{-1 \mathrm{c}}$ \\
\hline$\lambda$ & Mean free path of air & $0.66 \times 10^{-5} \mathrm{~cm}^{\mathrm{c}}$ \\
\hline$\rho_{\mathrm{a}}$ & Air density & $1.18 \times 10^{-3} \mathrm{~g} \mathrm{~cm}^{-3 \mathrm{c}}$ \\
\hline$\rho_{\mathrm{p}}$ & Particle density & $1.0 \mathrm{~g} \mathrm{~cm}^{-3 \mathrm{c}}$ \\
\hline
\end{tabular}

${ }^{\text {a }}$ Adopted from ICRP66 (ICRP, 1994).

b Adopted from Nazaroff et al. (1990).

c Adopted from Hinds (1999). 
deposition rate estimates $\left(\mathrm{h}^{-1}\right)$. The deposition rates for these PM may be determined beginning when the source generated by a certain indoor activity (e.g., cooking) is stopped. Deposition rates are estimated by taking the natural logarithm of both side of Eq. (7) for a given PM size range and regressing the natural logarithm of the indoor concentration on time,

$$
\ln C_{(t)}(k)=-\left(\lambda_{\mathrm{n}}+\lambda_{\mathrm{d}, \mathrm{m}}(k)\right) t+\ln C_{(t-1)}(k) .
$$

\subsection{PM inhalation dose in HRT}

The time-dependent concentration profiles of PM are used to calculate exposure doses through inhalation and represented as,

$$
D_{\mathrm{d}}(k, t)=\frac{\int_{0}^{t} C_{i}(k, t) d_{\mathrm{F}}(k) Q d t}{A_{i}},
$$

where $D_{\mathrm{d}}(k, t)$ is the time-dependent cumulative inhalation dose rate of PM per unit area of each lung region in the $k$ th size range (particles $\mathrm{cm}^{-2} \mathrm{~h}^{-1}$ ); $C_{i}(k, t), i=1,2,3,4,5 ; A_{i}$ is the surface area of airway wall in the compartment $i\left(\mathrm{~cm}^{2}\right)$; and $d_{\mathrm{F}}(k)$ is the PM deposition fraction of each lung region in the $k$ th size range and has the form as,

$$
d_{\mathrm{F}}(k, t)=\frac{C_{i}(k, t)}{C_{\mathrm{I}}(k, t)}\left[\left(\lambda_{\mathrm{d}_{i}}(k)+\lambda_{\mathrm{s}_{i}}(k)+\lambda_{i m_{i}}(k)\right) \frac{V}{Q}+\varepsilon_{i}(k)\right] .
$$

The differences in exposure can vary due to factors such as diameter of airways, breathing rate, PM profile, and time spent in the houses.

\section{Results and discussion}

\subsection{Indoor source rates and contributions}

Experimental results showed that the particle size distributions for four major indoor sources followed a lognormal distribution in that cooking and incense burning had geometric mean diameters (GMDs) (based on number) of $3.31 \mu \mathrm{m}$ and $1.52 \mu \mathrm{m}$ with geometric standard deviations (GSDs) of 1.79 and 2.88 , respectively. The measured overall indoor particle size distribution had a GMD of $1.71 \mu \mathrm{m}$ and a GSD 2.47. Results from the model calculations for indoor source emission rates of different size bins (Fig. 1A) indicated that incense burning had a larger emission rate $\left(0.08\right.$ particles $\left.\mathrm{s}^{-1}\right)$ for particle less than $1 \mu \mathrm{m}$, whereas cooking appeared to have a strong influence on indoor sources for particles larger than $2 \mu \mathrm{m}$ (emission rates range from $0.01-0.074$ particles $\mathrm{s}^{-1}$ ). Cooking and incense burning had higher sizeintegrated source emission rates of $0.042 \pm 0.024$ (mean \pm S.E.) and $0.048 \pm 0.026$ particles s $^{-1}$, respectively (Fig. 1B).
Cooking and incense burning were significant contributors to indoor particle levels for all particle sizes from 0.5 to $5 \mu \mathrm{m}$ (Fig. 1C) in that the percent contributions of cooking and incense burning to indoor concentrations were $0.334 \pm 0.02$ (mean \pm S.D.) and $0.267 \pm 0.035$, respectively. For the fine particles $(<2$ $\mu \mathrm{m})$, cooking and incense burning were the dominant contributors, whereas cooking, cleaning, and incense burning appeared to have a significant contributions to indoor concentrations for particle sizes between 2 and $5 \mu \mathrm{m}$ (Fig. 1C). In view of observed indoor and outdoor concentrations (Fig. 1D) and the model calculations, it demonstrates that for indoor particles from $0.5-5 \mu \mathrm{m}$, only $2.6-8 \%$ of indoor particles are from outdoor sources, whereas $62-92 \%$ of particles are from indoor sources, including cooking, incense burning, cleaning, and movement of people.

Table 3 shows the results from the model calculations for each of the 5 size fractions and the parameter estimates from multiple regression analysis of the impact of activities on indoor particle concentrations. The observed indoor and outdoor concentrations are also presented. Indoor and outdoor PM concentrations 

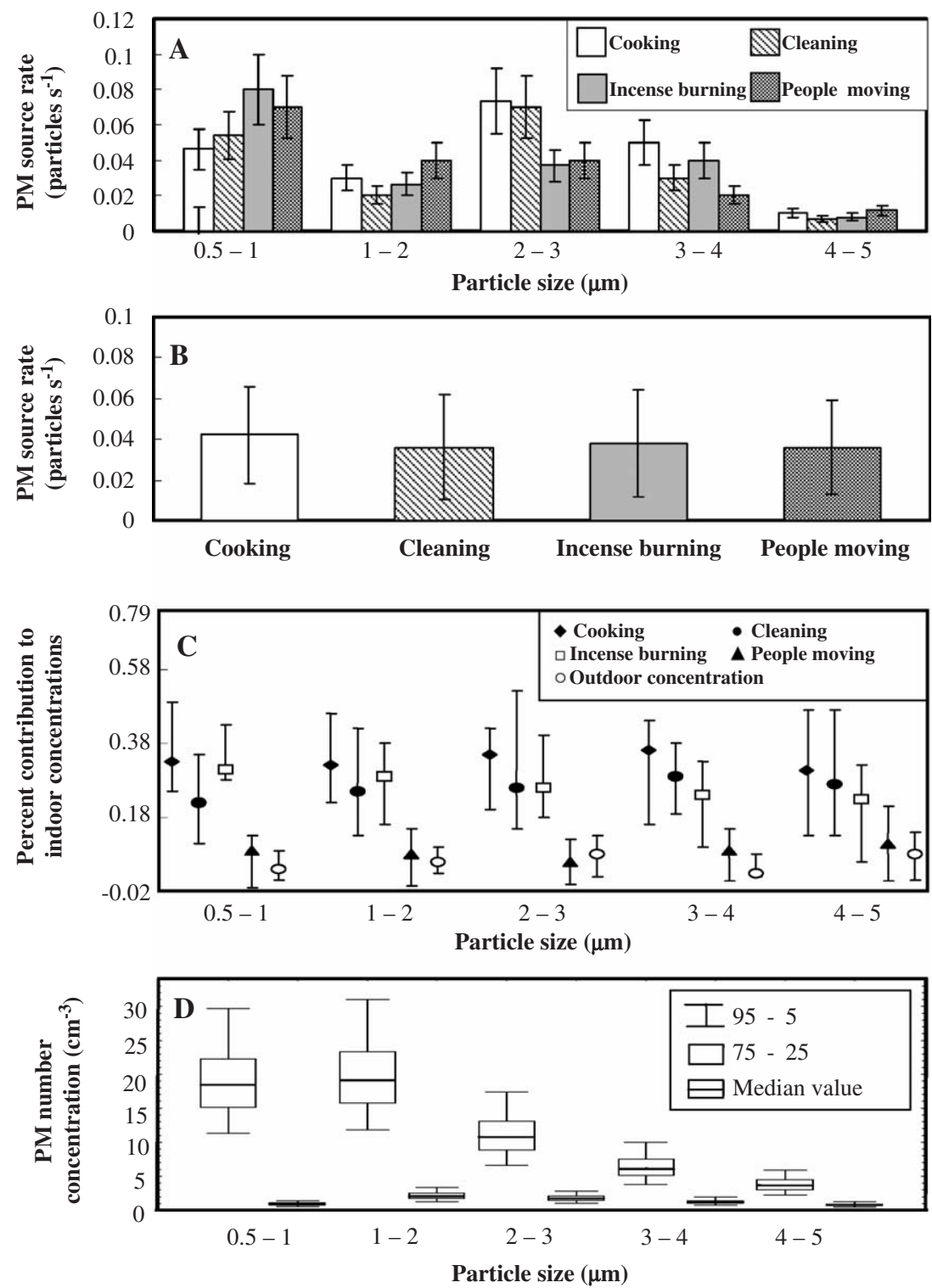

Fig. 1. (A) Source emission rate estimates from indoor activities for different particle size ranges derived from the multiple linear regression model, (B) size-integrated source rates. Error bars represent one standard error from the mean in that all $p$ values are less than 0.05, (C) percent contributions of indoor sources and outdoor concentration to indoor concentrations in that error bars represent the $95 \%$ confidence interval, and (D) observations of indoor (left-hand side) and outdoor (right-hand side) concentrations vary with particle sizes in that box and whisker shows the uncertainty.

increase with PM size intervals. The volume concentrations of fine particles were much lower than those of the coarse particles $(3-5 \mu \mathrm{m})$ due to the effect of particle diameter. Average emission rates were calculated to be $0.033 \pm 0.008,0.043 \pm 0.008,0.029 \pm$
0.007 , and $0.028 \pm 0.005\left(\mu \mathrm{m}^{3} \mathrm{~cm}^{-3} \mathrm{~min}^{-1}\right)$ for cooking, incense burning, cleaning, and people's moving, respectively. The overall order of magnitudes of emission rate were the same as those reported by Abt et al. (2000) yet obviously higher in the size 
Table 3

Parameter estimates from multiple regression analysis of the impact of activities on indoor particle concentrations

\begin{tabular}{|c|c|c|c|c|c|}
\hline & \multicolumn{5}{|l|}{ PM size intervals $(\mu \mathrm{m})$} \\
\hline & $0.5-1$ & $1-2$ & $2-3$ & $3-4$ & $4-5$ \\
\hline \multicolumn{6}{|c|}{ PM concentration $\left(\mu \mathrm{m}^{3} \mathrm{~cm}^{-3}\right)$} \\
\hline Indoor concentration & 10.02 & 282.32 & 732.67 & 1152.41 & 1457.37 \\
\hline Outdoor concentration & 0.48 & 30.94 & 118.40 & 227.97 & 312.84 \\
\hline \multicolumn{6}{|l|}{ Variables } \\
\hline Cooking $\left(\min ^{-1}\right)$ & $0.036(0.029-0.048)^{\mathrm{a}}$ & $0.056(0.044-0.074)$ & $0.023(0.018-0.031)$ & $0.033(0.027-0.044)$ & $0.167(0.133-0.222)$ \\
\hline Cleaning $\left(\min ^{-1}\right)$ & $0.031(0.025-0.041)$ & $0.083(0.067-0.11)$ & $0.024(0.019-0.032)$ & $0.056(0.044-0.074)$ & $0.253(0.202-0.337)$ \\
\hline Incense burning $\left(\min ^{-1}\right)$ & $0.021(0.017-0.028)$ & $0.063(0.05-0.084)$ & $0.04(0.036-0.060)$ & $0.042(0.033-0.056)$ & $0.208(0.167-0.278)$ \\
\hline Peoples moving $\left(\mathrm{min}^{-1}\right)$ & $0.024(0.019-0.032)$ & $0.042(0.033-0.056)$ & $0.042(0.033-0.056)$ & $0.083(0.067-0.085)$ & $0.142(-0.095-0.182)$ \\
\hline
\end{tabular}

${ }^{\mathrm{a}} \mathrm{A}(\mathrm{B}-\mathrm{C})$ denotes $\mathrm{A}$ an average, $\mathrm{B}$ a minimum, and $\mathrm{C}$ a maximum.

intervals $3-4$ and $4-5 \mu \mathrm{m}$. This may cause a relative high volume concentration in coarse particle. A comparison with Abt et al. (2000) shows that both the magnitude of PM concentrations and the trend of PM concentrations versus size intervals founded in the residence in central Taiwan region appear to be extremely different. The difference might be related to the cooking strategy, incense specification, and ventilation rate in the traditional Taiwanese home.

Cooking and incense burning are two major sources to increase PM concentrations. Comparing our results with Abt et al. (2000), in which cooking and cleaning have the significant contributions to increase $\mathrm{PM}_{(0.7-10)}$ concentrations, shows the important information that contributions of cooking in indoor PM concentrations by $0.27 \mu \mathrm{m}^{3} \mathrm{~cm}^{-3} \mathrm{~min}^{-1}$.

The overall decay rate estimate (including deposition and air exchange rates) from cooking events is determined to be $0.59 \mathrm{~h}^{-1}$ (Fig. 2A,B) in that the sizedependent deposition rate estimates are also calculated (Fig. 2C). It is evident that there is variability in the deposition rate estimations in that a greater variability appears in the particles larger than $2.5 \mu \mathrm{m}$. This variability may be due to the inputs of model parameter such as Brownian diffusion, whereas in the realistic conditions the housing structure, the dominant flow regimes, deposition surface materials, coagulation of smaller particles, indoor and outdoor temperatures, and room air mixing patterns that occurs while particles are decaying also result in the variability.

Fig. 2C shows that the deposition rates from cooking events increase with particle size, with mean deposition rates of $0.01 \mathrm{~h}^{-1}$ for $1-3 \mu \mathrm{m}$ particles, increasing up to $0.06 \mathrm{~h}^{-1}$ for $3-5 \mu \mathrm{m}$ particles. This increase in deposition rates with particle size is expected since gravitational settling is the dominant mechanism for particles in these size ranges. Deposition rates for 3-4 and 4-5 $\mu \mathrm{m}$ particles of 0.047 and $0.109 \mathrm{~h}^{-1}$ were comparable to values of 0.037 and $0.10 \mathrm{~h}^{-1}$ calculated from the $\mathrm{C}-\mathrm{S}$ deposition model, respectively.

Results from the multiple regression models suggest that there are more indoor sources of coarse particles than the fine particles based on air exchange rate of $\mathrm{LN}\left(0.52 \mathrm{~h}^{-1}, 1.82\right)$. Cooking, cleaning, and people's moving significantly increased indoor concentrations for particles larger than about $\mathrm{PM}_{2.5}$, yet some unknown sources may be attributed to resuspension from people's movement, which may produced $\mathrm{PM}_{2.5}$ concentrations that were comparable to levels generated by cooking and cleaning. From the time-activity data, outdoor particles ( $\mathrm{LN}(2.68 \mu \mathrm{m}$, 2.21)) were found to be insignificant contributors to overall indoor particles levels $(\mathrm{LN}(1.71 \mu \mathrm{m}, 2.88))$ in that the indoor-outdoor ratios without the indoor sources (i.e., $\beta_{\mathrm{o}}(k)$ values) were ranged from 0.04 0.08 (Fig. 1C,D).

The decay rate measurements from cooking events indicate that the significant variability existing in estimates may be due to differences in house temperature gradients, surface materials, airflow patterns, and volumes. Because measured deposition rates were higher than theoretical estimates, suggesting that concentration and/or temperature gradients created by cooking events may increase the mixing rate of room air resulting in higher deposition rates of particles to surfaces. Further investigation of this issue is required. 

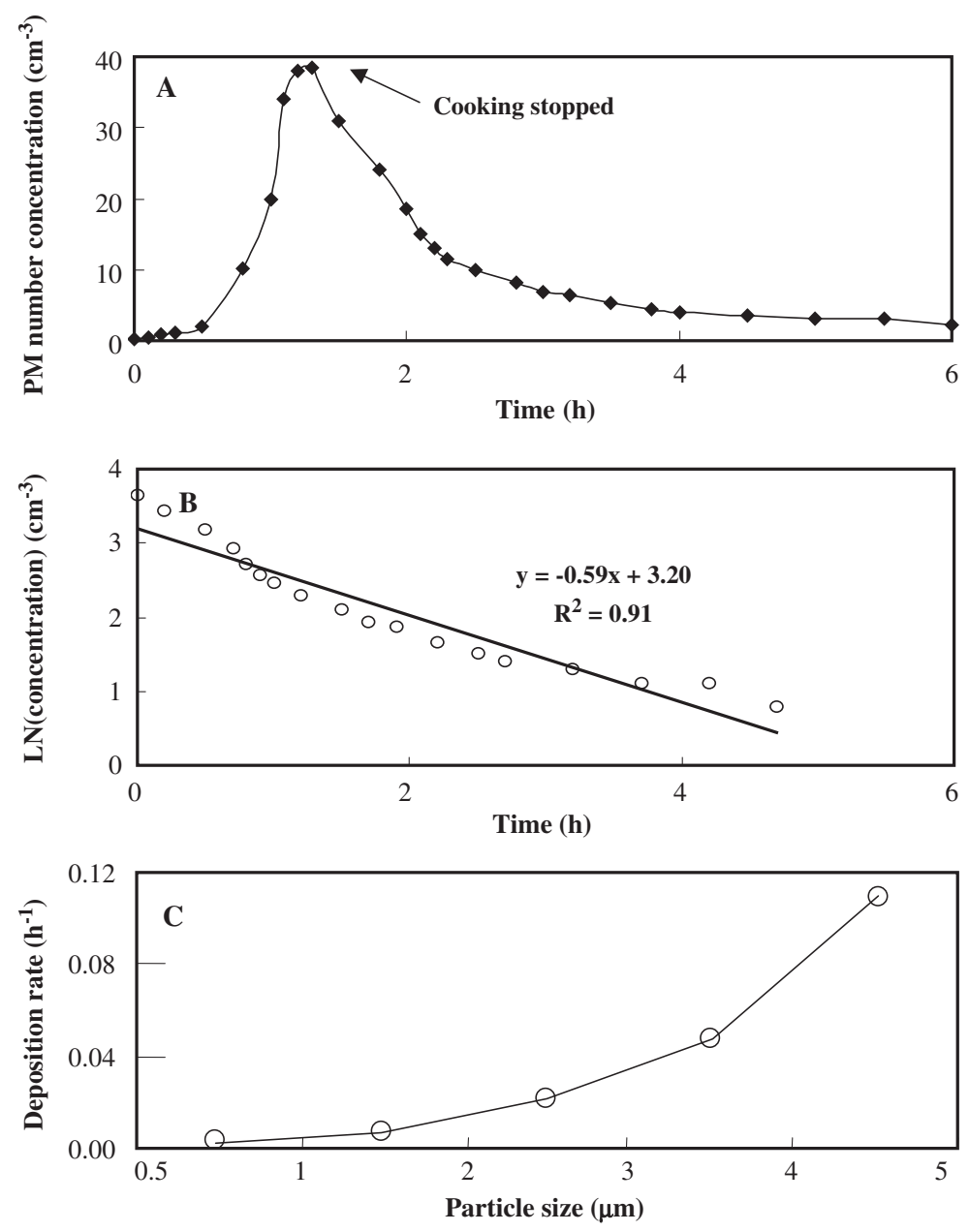

Fig. 2. (A) Source emission and decay of PM from an indoor cooking event where data illustrate the decay curve that is modeled to estimate a decay rate, (B) plot of the decay of PM when the cooking event is stopped where data are represented as the natural logarithm of concentrationtime profile, and $(\mathrm{C})$ deposition rate estimates from cooking event for different particle size ranges.

\subsection{Indoor sources $L / I$ relationships}

Because the PM concentrations within the five compartments reach the steady state in $5-10 \mathrm{~s}$ for all the size ranges, it is more important to understand the $\mathrm{PM}$ mass L/I ratio, deposition fraction, and inhalation exposure dose than the dynamics of PM in HRT. Comparing the concentrations in $\mathrm{ET}_{1}$ with $\mathrm{AI}$ compartments, the deeper lung region had a lower PM concentration as a result of the deposition made the $\mathrm{PM}$ no longer airborne especially in bigger size ranges of bin $4(3-4 \mu \mathrm{m})$ and bin $5(4-5 \mu \mathrm{m})$ (Fig. 3). Fig. 3 indicates that equilibrium PM number concentrations in HRT induced from incense burning (0.083-0.37 $\left.\mathrm{cm}^{-3}\right)$ are greater than that induced from cooking events $\left(0.008-0.133 \mathrm{~cm}^{-3}\right)$.

Generally, the GMDs of particle size distributions of PM from cooking events in lung regions are larger than that from incense burning (Fig. 3); result in different PM number distribution patterns in lung regions. Fig. 3 illustrates the integrated cumulative inhalation dose rates in different HRT regions, indicating that $\mathrm{ET}_{1}$ (23.94-24.27), BB (4.29-5.06), and bb (4.97-10.82 particles $\mathrm{cm}^{-2} \mathrm{~h}^{-1}$ ) regions have higher 


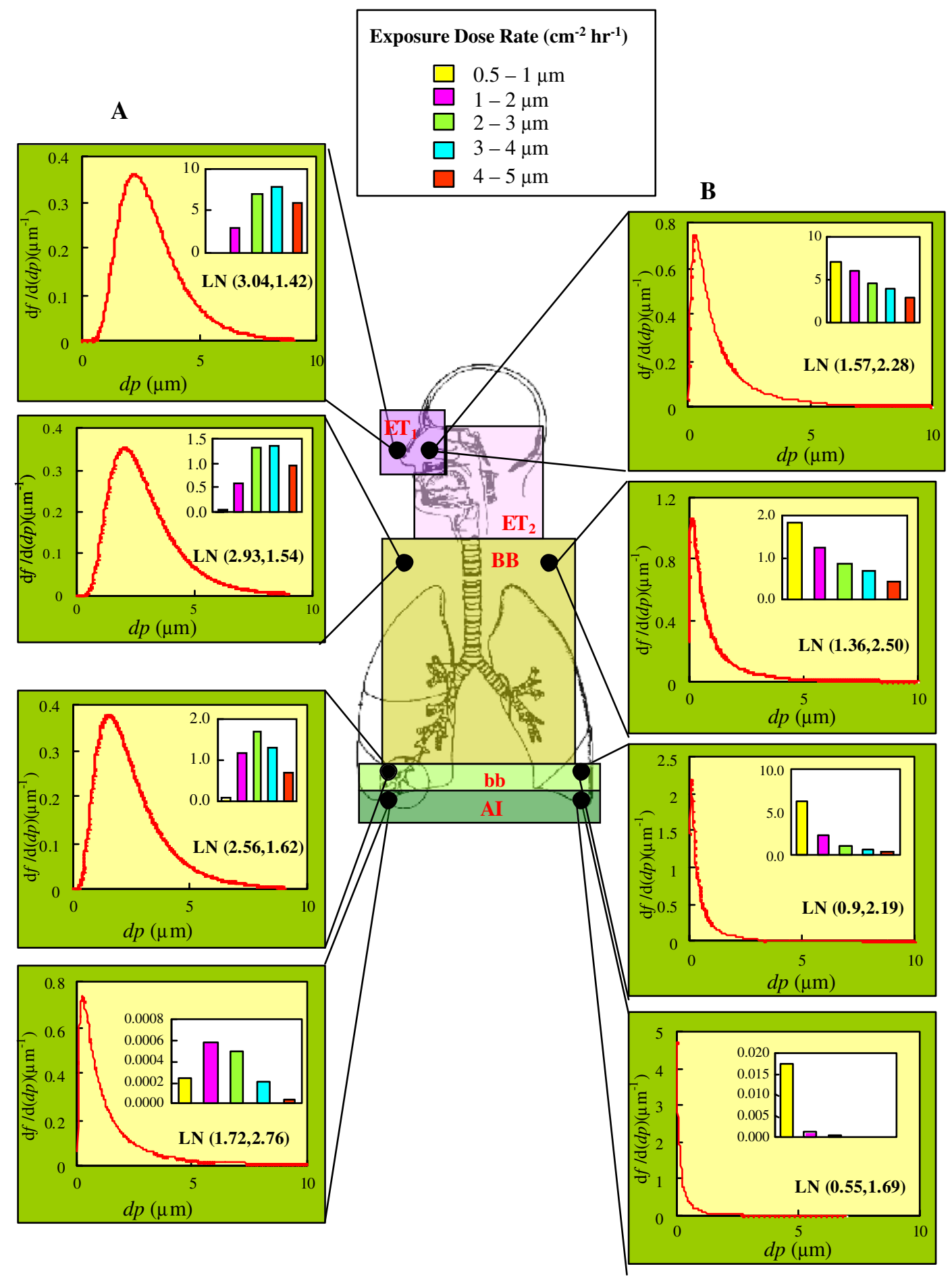

Fig. 3. Particle size distributions and size-dependent exposure dose rates in different HRT regions from (A) cooking and (B) incense burning events. 
inhalation dose rates than that of in AI region (0.0020.02 particles $\mathrm{cm}^{-2} \mathrm{~h}^{-1}$ ) for both cooking and incense burning events.

The dominant deposition mechanism in HRT is found to be the inertial impaction rate, in which the deposition rate increased both with increasing PM sizes and decreasing airway diameters. The orders of magnitude of turbulent diffusive deposition, gravitational settling, and inertial impaction rates are $10^{-5}$ $10^{-3}, 10^{-3}-10^{-2}$, and $10^{-3}-10^{0} \mathrm{~s}^{-1}$, respectively, for particle sizes in the range of 0.5 to $5 \mu \mathrm{m}$. Based on our simulations, the interception deposition efficiency is relatively small compared with the other deposition rates. The orders of magnitude of interception deposition efficiency are $10^{-10}-10^{-4} \%$ in all the HRT regions, and may neglected based on the mathematical point of view.

Generally, the lung regions of $\mathrm{ET}_{1}$ and $\mathrm{ET}_{2}$ had higher PM mass L/I ratios $(0.70-0.83)$ than that of lung regions $\mathrm{BB}(0.41-0.62)$, bb $(0.12-0.41)$, and AI $(0.02-0.26)$ for each size bin in that larger bin sizes have smaller PM mass L/I ratios from both cooking

A

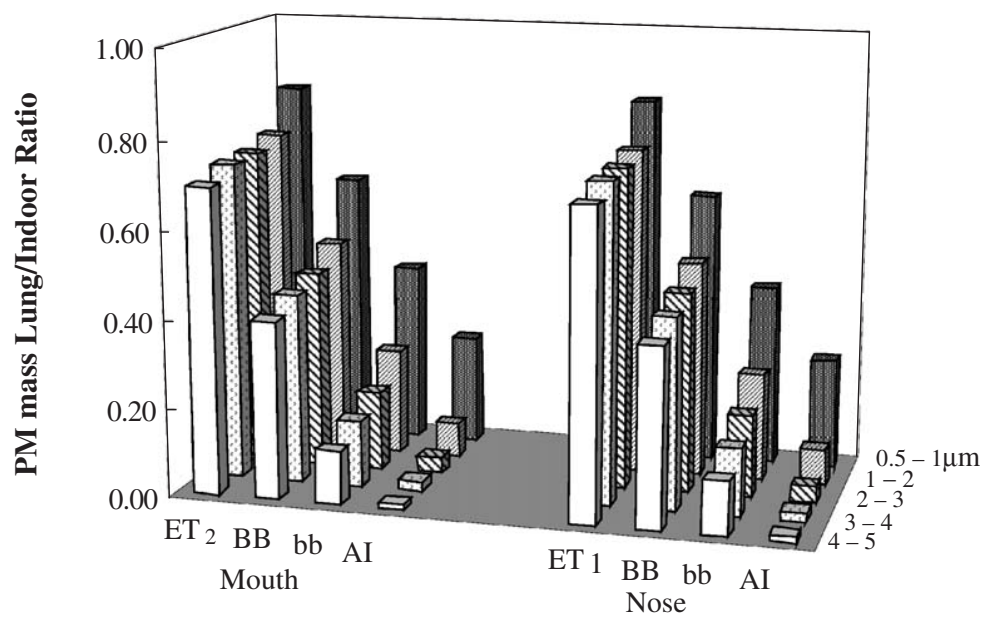

B

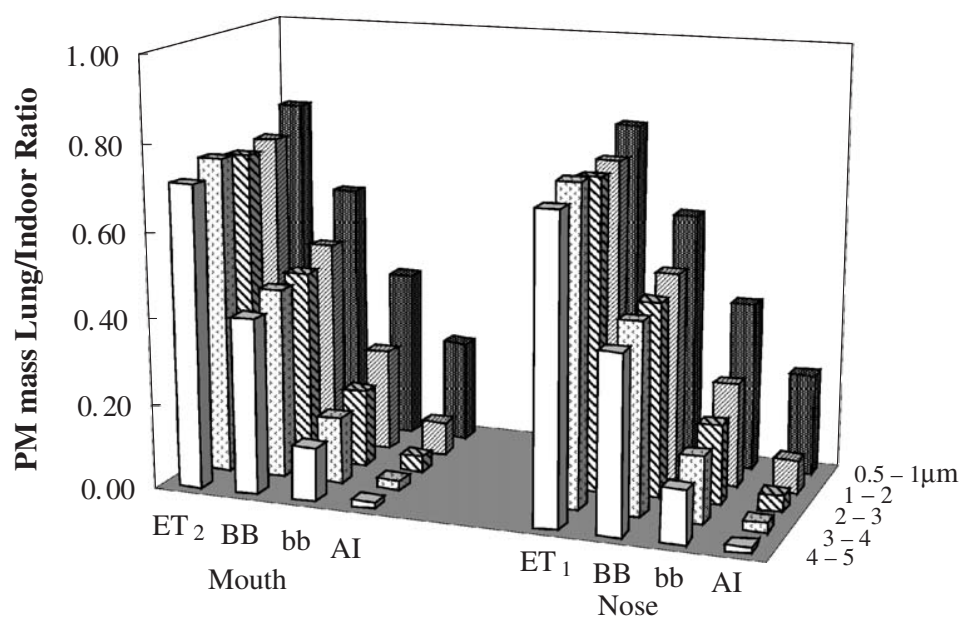

Fig. 4. Calculated PM mass lung/indoor ratios for each particle size range in different HRT regions during mouth and nose inhalation from (A) cooking and (B) incense burning events. 
and incense burning events (Fig. 4). The cooking and incense burning events have similar distribution patterns of PM mass L/I ratio (Fig. 4).

\section{Conclusions}

Detailed time-activity data incorporating with realtime indoor and outdoor particle size distribution information provide a practical approach to estimate apparent indoor source emission rates and major contributions to indoor concentrations. Our results revealed that cooking and incense burning events were major contributors to indoor concentrations for the particle sizes $1-5 \mu \mathrm{m}$, providing that this valuable information was directly relevant to actual personal exposures.

The dominant deposition mechanism in the lung regions was found to be the inertial impaction rate, in which the ranged order of magnitude was $10^{-3}-10^{-1}$ $\mathrm{s}^{-1}$. Our results demonstrated that extrathoracic region had higher average PM mass lung/indoor ratios (0.77) than that of bronchial $(0.52)$, bronchiolar (0.27), and alveolar-interstitial (0.14) regions from both cooking and incense burning events.

Our results demonstrated the importance of knowing both the time-activity data and the real-time indoor and outdoor particle size distribution information for understanding exposure to particles of indoor sources. More importantly, this research illustrates that an exposure assessment based on $\mathrm{PM}_{(0.5-5)}$ measured indoors can provide valuable information on the fate of indoor particles and hazard to human health. Further study is required for extension of these results to multi-story residential environments that primary involve the dynamics of transport into and within the multiple zones that are present in these types of residences.

\section{References}

Abt E, Suh HH, Catalano P, Koutrakis P. Relative contribution of outdoor and indoor particle sources to indoor concentrations. Environ Sci Technol 2000;34:3579-87.

Chang LT, Koutrakis P, Catalano PJ, Suh H. Assessing the importance of different exposure matrics and time-activity data to predict 24-h personal $\mathrm{PM}_{25}$ exposures. J Toxicol Environ Health A 2003;66:1825-46.

Crump JG, Seinfeld JH. Turbulent deposition and gravitational sedimentation of an aerosol in a vessel of arbitrary shape. J Aerosol Sci 1981;12:405-15.

Hinds WC. Aerosol technology: properties, behavior, and measurement of airborne particles, 2nd edition. New York: Wiley; 1999.

Howard-Reed C, Wallace LA, Emmerich SJ. Effect of ventilation system and air filters on decay rates of particles produced by indoor sources in an occupied townhouse. Atmos Environ 2003; 37:5295-306.

ICRP. Human respiratory tract model for radiological protection, a report of a task group of the international commission on radiological protection. ICRP Publication. New York: Elsevier; 1994.

Lai AK, Nazaroff WW. Modeling indoor particle deposition from turbulent flow onto smooth surfaces. J Aerosol Sci 2000;31: $463-76$

Liao CM, Chen JW, Huang SJ. Size-dependent PM10 indoor/outdoor/personal relationships for a wind-induced naturally ventilated airspace. Atmos Environ 2003;37:3065-75.

Liao CM, Huang SJ, Yu H. Size-dependent particulate matter indoor/outdoor relationships for a wind-induced naturally ventilated airspace. Build Environ 2004;39:411-20.

Lowengart RA, Peters JM, Cicioni C, Buckley J, Bernstein L, Preston-Martin S, et al. Childhood leukemia and parents' occupational and home exposures. J Natl Cancer Inst 1987;79: $39-46$.

Lung SCC, Hu SC. Generation rates and emission factors of particulate matter and particle-bound polycyclic aromatic hydrocarbons of incense sticks. Chemosphere 2003;50:673-9.

Lung SCC, Kao MC, Hu SC. Contribution of incense burning to indoor $\mathrm{PM}_{10}$ and particle-bound polycyclic aromatic hydrocarbons under two ventilation conditions. Indoor Air 2003;13: 194-9.

Nazaroff WW, Ligocki MP, Ma T, Cass GR. Particle deposition in museums: comparison of modeling and measurement results. Aerosol Sci Technol 1990;13:332-48.

Preston-Martin S, Yu MC, Benton B, Henderson BE. N-nitroso compounds and childhood brain tumors: a case-control study. Cancer Res 1982;42:5240-5.

Zhong LJ, Goldberg MS, Gao YT, Jin F. Lung cancer and indoor air pollution arising from Chinese-style cooking among nonsmoking women living in Shanghai, China. Epidemiology 1999;10: $488-94$. 